\title{
Irish GMS Cost Projections and Its Implications between 2016 and 2026
}

\author{
Conway Lenihan $\mathrm{A}^{1^{*}}$ and Woods $\mathrm{N}^{2}$ \\ ${ }^{1}$ Department of Management and Enterprise, Cork Institute of Technology, Rossa Avenue, Bishopstown, Cork City, Ireland \\ ${ }^{2}$ Centre for Policy Studies, University College Cork, 6 Bloomfield Terrace, Western Road, Cork, Ireland
}

"Corresponding Author: Aisling ConwayLenihan, Department of Management and Enterprise, Cork Institute of Technology, Rossa Avenue, Bishopstown Cork, Ireland, Tel: +353214335924; E-mail: aisling.conway@cit.ie

Received date: September 18, 2015; Accepted date: October 26, 2015; Published date: November 07, 2015

Copyright: ( 2015 Lenihan AC, et al. This is an open-access article distributed under the terms of the Creative Commons Attribution License, which permits unrestricted use, distribution, and reproduction in any medium, provided the original author and source are credited.

\section{Abstract}

Introduction: Ireland had one of the highest pharmaceutical spends per capita in the EU in 2012. The General Medical Services (GMS) scheme is the largest community drug scheme in Ireland with approximately $40 \%$ of the population eligible for free drugs and appliances in 2012. The total cost of GMS prescriptions increased by $414 \%$ between 1998 and 2012. This paper projects Irish GMS cost from 2016 to 2026 and examines the implications of the estimated impact on GMS expenditure.

Method: Central Statistics Office (CSO) population projections (2013) and HSE-PCRS GMS population prescription data (2012) were used to develop four variables; population, GMS coverage, average cost per claimant and claims rate. A Monte Carlo Simulation (MCS) model simulated the effect of these four variables on GMS costs, by health board region, age cohort and sex.

Results: Irish population is projected to grow by approximately $10 \%$ between 2012 and 2026 . The over 70 s population is estimated to grow by $64 \%$ with the proportion of males growing by $72 \%$. GMS expenditure is estimated to increase by $64 \%$, from $€ 1.1$ billion in 2016 to $€ 1.8$ billion by 2026 . Age is a key driver of GMS expenditure, specifically those aged under 11 and over 70 . The MCS results project that males, the Mid-Western and SouthEastern regions are driving GMS costs in the under 11s. Females, Midlands and Southern regions are driving GMS costs in the over 70 s.

Conclusion: Population growth coupled with an aging population will impact future GMS costs. Targeted GMS policy changes such as co-payment charges, reference pricing, and generic substitution can help to contain future GMS expenditure.
\end{abstract}

Keywords: Monte carlo modelling; Drug prescribing; Pharmaceutical expenditure; GMS

\section{Introduction}

In 2012, Ireland spent $14 \%$ of total government expenditure on healthcare which is comparable with the European Union (EU) average, EU28. The Netherlands had the highest proportion at $20 \%$ and Cyprus had the lowest proportion at $8 \%$. Irish health spending accounted for $8.9 \%$ of Gross Domestic Product (GDP), just above the EU28 average of $8.7 \%$. Netherlands recorded the highest value at $11.8 \%$ and Romania the lowest at 5.6\% [1]. According to a 2015 Organisation for Economic Co-Operation and Development (OECD) report, Ireland spent $1.3 \%$ less on health between 2007 and 2013 [2]. Irish pharmaceutical expenditure per capita relative to other OECD countries has increased significantly since 2000 . Ireland's position has moved from 20th highest of 27 countries in 2000 to 3rd highest of 25 countries in 2010. In 2010, Irish per capita spending on pharmaceuticals was the highest in the EU and was $34 \%$ above the EU average [3]. The Irish government has introduced cost containment measures during the economic crisis to combat this trend such as copayment charges for patients, GMS eligibility criteria, reference pricing and generic substitution promotion [4]. Despite these cost containment measures, Irish pharmaceutical spending per capita in
2012 was the third highest amongst EU countries at $€ 500,40 \%$ above the EU average (€350) [1].

There are eleven community drug schemes in Ireland, where a person has entitlement to free or subsidised healthcare. The four most expensive schemes are the General Medical Services Scheme (GMS), Drug Payments Scheme (DPS), High Tech Drug Scheme (HTDS) and Long Term Illness (LTI) scheme. The GMS scheme is the largest community drug scheme in Ireland. $40.40 \%$ of the population $(1,853,877$ persons) were eligible for the GMS (also known as medical card scheme) in 2012, the highest it has been since data was published in $1996(1,252,385-34.5 \%)$ [5]. Any eligible GMS person is entitled to free medicines and appliances. Eligibility is determined by income guidelines and persons who are affected by certain medical conditions. The GMS scheme is financed by the state with a contribution from each GMS eligible person. Since October 2010, each person on the scheme incurred a $€ 0.50$ charge for every prescription item dispensed up to a maximum of $€ 10$ per family per month. This was subsequently increased to $€ 1.50$ in 2013 and is currently $€ 2.50$ per prescription item up to a maximum of $€ 25$ per family per month.

GMS coverage rates (proportion of the population who has a medical card) peaked in 2012 and have fallen to $1,849,380(40.3 \%)$ in 2013 and to $1,804,376(39.3 \%)$ in July 2014 . This decrease may be partly attributed to a reduction in the number of discretionary medical 
Page 2 of 7

cards issued, which decreased from 63,126 in 2012 to 50,294 in 2013 [6]. Discretionary medical cards are awarded when significant medical costs are incurred as a result of illness and are unable without undue hardship to arrange GP medical and surgical services for themselves [7]. The total cost of GMS prescriptions has increased from €249 million in 1998 to $€ 1.28$ billion in 2012, a $414 \%$ increase (various annual PCRS Reports - 1998-2012). GMS prescription expenditure rose rapidly after 2000 . It increased by $290 \%$ from approximately $€ 328$ million in 2000 to $€ 1.28$ billion in 2012. GMS expenditure accounted for $9 \%$ of the overall health budget in 2012 [8]. There are number of factors identified in the literature that influence drug expenditure; population, population aging, inflation, price effects, volume effects, mix of drugs, sex and age [9-12].

Modelling health and drug expenditure varies considerably internationally. A number of studies on health expenditure projections based on historical trends have been carried out in the US [13-15]. The three studies estimated national health expenditure based on assumptions around economic (varying levels of economic growth) and demographic variables for a 10 year period. Another US study developed projections on drug expenditure and incorporated historical trends in drug expenditure and expected changes in the drugs market that may influence drug expenditure in 2015 [16]. A French study forecasted national drug expenditure based on demographic and epidemiological factors out to 2029, using a Markovian microsimulation model [17]. A Swedish study forecasted drug expenditure in the region of Stockholm over a two year period, 2010-2011. They used a linear regression analysis and applied it to historical drug sales between 2006 to 2009 [18]. Based on expert opinion and a review of the literature, a Monte Carlo Simulation (MCS) was deemed to be the most appropriate model to use.

A 2014 study by Conway et al [19] projected GMS costs for Ireland in five year intervals to 2026, using 2008 Central Statistics office (CSO) population projections. This study estimated that GMS expenditure is estimated to increase from $€ 1.1$ billion in 2011 to $€ 1.9$ billion by 2026 . The conclusions drawn were that age $(<11$ and $>70)$, females and the Midlands region were found to have the most significant effect on future GMS costs in Ireland. Since then, the CSO [20] has revised its population projections downwards and following the onset of the financial crisis, the Irish government has introduced cost containment measures. This paper adds to the literature by utilising updated CSO population projections and 2012 GMS population prescription data.

The aim of this paper is to project Irish GMS cost from 2016 to 2026 and to examine the implications of the estimated impact on GMS expenditure.

\section{Method}

To estimate GMS costs to 2026, we used a MCS model to simulate various scenarios, using the latest CSO population projections and 2012 Health Service Executive-Primary Care Reimbursement Service (HSE-PCRS) population GMS prescription data. From this data, four variables were developed; population, GMS coverage rates, claims rate and average cost per claimant. Three scenarios were formulated for each variable; low variable growth (best case scenario - minimum), average variable growth (most likely scenario - mean) and high variable growth (worst case scenario - maximum).

\section{CSO population data}

The CSO regional population projections 2016-2031 [20] provided updated projections based on the 2011 Irish census. Data was detailed by year of age, sex, county and region, incorporating assumptions around mortality, fertility, international and internal regional migration. The revised downward CSO population projections are mainly driven by a fall in fertility. We aggregated the population data into ten HSE cohorts so comparisons can be made with earlier research [19]. An adjustment factor based on the 2011 census was applied as three of the CSO regions (Border, Mid-East, Dublin) did not conform to three of the old health board regions (North-West, North-East, Eastern). There are eight regions (Eastern, South-Eastern, Southern, Western, Mid-West, Midlands, North-West and North-East) within the old health board structure in Ireland.

\section{GMS coverage rates}

GMS coverage rates are the proportion of the population who have a medical card. 2012 mean coverage rates by the old health board region, sex and age cohort were estimated using the 2012 PCRS annual report and CSO population projections. The minimum, mean and maximum coverage rates were estimated using historical data between 1996 and 2012. These three scenarios formed the basis of projections for 2016, 2021 and 2026. The projected mean population was used to estimate the coverage rates and the number of eligible persons for each scenario in 2016, 2021 and 2026.

\section{GMS HSE-PCRS database}

HSE-PCRS population GMS dataset (2009-2012) and N=60 million for each year. The data is detailed per prescription item (observation). There are 40 variables in the database, of which seven are specific to this research. These include; HSE Local Health Office (LHO) number, year of age, sex, dispense number and total cost (ingredient cost, Value Added Tax (VAT) and dispensing fee). Any person can register with their LHO (32 offices) to determine eligibility for the GMS scheme. A unique dispense number is allocated to each GMS claimant for all prescription items in an individual year. A claimant is a person who has a GMS medical card and makes a claim on that card. If a claimant is issued a replacement medical card within any specific year, they will be allocated a new dispense number. The data was aggregated and analysed by the old health board region (8). The data was cleaned as some data had no sex or age. The year of age variable was aggregated into the eleven HSE age cohorts ranging $<5$ 's to the $>75$ 's. For the purpose of comparison, the age cohorts, $<5$ and 5-11 were summed together for the four variables. Data management and analysis was carried out in Microsoft Excel and R-Studio version 2.15.3. HSE-PCRS population GMS dataset (2009-2012), combined with the annual 2012 PCRS report [5] was used to formulate the average cost per claimant and claims rate variables.

\section{Claims rate}

The claims rate is the proportion of the GMS population who make a claim. 1,853,877 held medical cards in Ireland in 2012, of which, $1,649,950$ made a claim (claims rate $=89 \%$ ). Historical national and regional claims rates were calculated to determine lower and upper bound values around the mean claims rate. Between 2005 and 2012, the lowest national claims rate was $88 \%$ and the highest national claims rate was 95\% (2007 levels) and these formed the minimum and maximum scenarios respectively. The mean claims rate in 2012 was 
scaled by the minimum national and regional claims rate values to determine the lower bound claims rate scenario 2012 by region, sex and age cohort. 2007 claims rate values by region, sex and age cohort were taken as the upper bound scenario for 2012 [19]. For this analysis, the claims rate was assumed to remain at 2012 estimated levels (3 scenarios) over the lifetime of the projections.

\section{Average cost per claimant}

The average cost per claimant is the total cost of claimants divided by the number of claimants and this was calculated using the 2012 HSE-PCRS population dataset. The average cost per claimant variable was updated using HSE-PCRS 2009 to 2012 population data and this formed the basis of our projections whereas the previous research [19] was based on a sample 2007 HSE-PCRS GMS database. Historical average cost per claimant data was determined from the HSE-PCRS population database between 2009 and 2012. There is considerable variation in the data year on year. The minimum, mean and maximum growth rates between 2009 and 2012 were calculated by age cohort and sex. This variation may be explained by the Irish economic crisis, an increase in GMS eligibility rates and health expenditure cuts. Therefore, a four year average cost per claimant between 2009 and 2012 was deemed appropriate given the variability in the data and this formed the most likely scenario for 2012 and the base for projections of this variable. Upper bound and lower bound 2012 scenarios were estimated around the mean cost per claimant. Initially, various percentiles and the inter-quartile range were determined, but showed significant variation in the data. Therefore, we estimated lower and upper bounds for 2012 around the mean cost per claimant (mean \pm $5 \%)$.

The four year average cost per claimant $\pm 5 \%$ formed the basis of projections between 2016 and 2026. For average cost per claimant projections, the minimum, mean and maximum annual growth rates were determined between 2009 and 2012. As the historical data showed significant variation between 2009 and 2012, projections based on these growth rates were not deemed appropriate. A four year average of the health inflation rate between 2009 and 2012 was calculated (2\%) and this was applied annually between 2012 and 2026 [21]. The minimum 2012 average cost per claimant (scenario 1) values by region, sex and age cohort were uniformly increased by $2 \%$ to determine 2016 scenario 1 average cost per claimant by region, sex and age cohort. For example, a male in the Eastern region in the 0-11 age cohort has an average cost per claimant value of $€ 107.80$ in 2012 . This value was increased annually by $2 \%$ up to 2016 to estimate the average cost per claimant of $€ 116.69$ for 2016 . The following formula (Eq1) was applied to each of the 160 cells (age cohorts (10), sex (2) and regions (8));

Min ac per claimant 2016=min ac per claimant $2012(1+0.02) 4(1)$

This methodology was applied to all three scenarios to determine three 2016 scenarios. Using the same methodology average cost per claimant 2016 (3 scenarios) and 2021 (3 scenarios) was increased by $2 \%$ uniformly across region, sex and age cohort to determine average cost per claimant 2021 and 2026 respectively.

The Cost projection model (Eq 2) is as follows;

Total Cost $=\mathrm{f}$ (Population, GMS Coverage, AC per Claimant, Claims Rate) (2)
MCS model was employed due to the uncertainty around the input parameters. The input parameters are population, coverage, claims rate and average cost per claimant based on 2012 data. MCS was employed to propagate the parameter uncertainty through 100,000 iterations. Each input variable is comprised of age cohorts (10), sex (2) and regions (8) giving a total of 160 cells to be modelled for each variable. The dependent variable is the projected total GMS cost for 2016, 2021 and 2026. Taking a large number of simulations $(100,000)$, gives an approximation to the true distribution of projected cost. The equation (Equation: 3) used for simulations is;

Probable cost=Expected cost+error (3)

In order to prepare the data for Monte Carlo Simulations, the probability and cumulative probability of finding a person within each region, sex and age cohort class were calculated. A macro was written in Visual Basic Editor in Microsoft Excel to run the simulations. It's important to assign an appropriate probability distribution to uncertain variables in developing a comprehensive MCS model [22]. A normal distribution was applied to estimate costs to allow for uncertainty in the model. The Central Limit Theorem was applied, which states that the sum of random variables will be approximately distributed [23]. The MCS results were imported into Minitab for analysis. All statistical analyses were performed using Minitab statistical package (Minitab 17).

\section{Results}

This section includes a descriptive analysis followed by an empirical analysis.

\section{National population projections}

The population of Ireland is estimated to grow from 4.6 million to 5.0 million, an increase of almost $10 \%$ between 2012 and 2026 in Figure 1. The female population is estimated to grow by $10.5 \%$, whereas the male population is estimated to grow by $9.5 \%$. The updated population projections in Table 1 are more conservative than the Conway et al. [19] projections.

\begin{tabular}{|l|l|l|}
\hline Year & Current Projections & $\begin{array}{l}\text { Conway et al (2014) Population } \\
\text { Projections }\end{array}$ \\
\hline 2012 & 4.6 & 4.7 \\
\hline 2016 & 4.7 & 5.1 \\
\hline 2021 & 4.9 & 5.4 \\
\hline 2026 & 5.0 & 5.7 \\
\hline Source: [19] & & \\
\hline
\end{tabular}

Table 1: Comparison current population projections (Million) with Conway et al (2014) Projections. 
Page 4 of 7

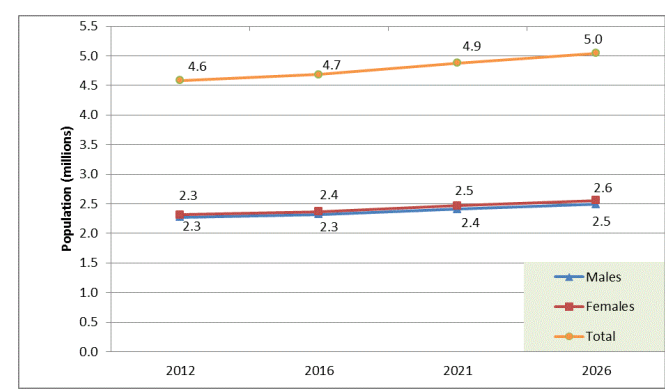

Figure 1: Estimated Population Growth 2012-2026.

The elderly population is those aged $65+$ but this paper focuses on the over 70's population as this age group is entitled to free medical care on the GMS scheme. The over 70's include two age cohorts, 70-74 and $>75$ 's. The over 70 s population is estimated to grow by $64 \%$ between 2012 and 2026 in Figure 2. The male population is estimated to grow by $72.2 \%$ and the female population is expected to grow by $57.6 \%{ }^{1}$.

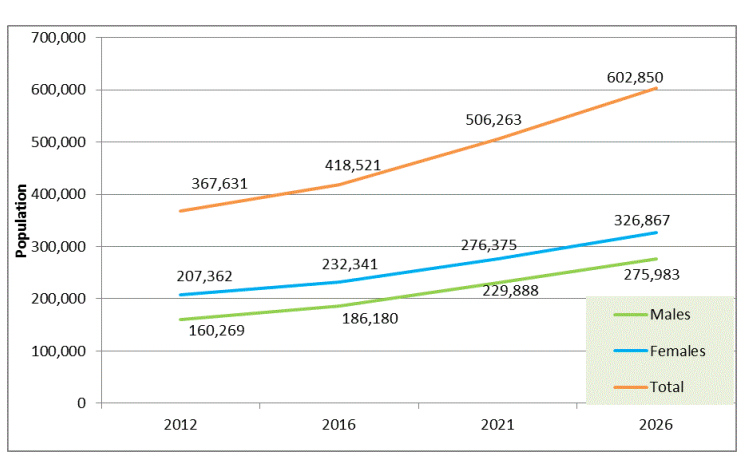

Figure 2: Estimated Population Growth for those aged 70 and over, 2012-2026.

The dependency ratio (ratio of population aged 65+ to the population aged 18-64) indicates the likely impact of population aging. The dependency ratio is estimated to increase from 0.21 in 2016 , to 0.24 in 2021 and 0.27 in 2026. The inverse (ratio of population aged 18-64 to the population aged 65+) shows those of working age who support the older population of $65+$. It decreases from 4.54 in 2016, to 3.95 in 2021 to 3.49 in 2026.

\section{Regional population projections}

Regional population is expressed as a proportion of the national population ${ }^{2}$. In 2012 , we estimated that $35.3 \%$ of the population live in the Eastern region but this is projected to increase to $37.2 \%$ by 2026 . Three regions, Midlands, North-West and the South-East region are estimated to grow slightly between 2012 and 2016 and decrease thereafter. The remaining four regions are forecasting a population decrease over the lifetime of the projections.

\section{GMS coverage projections}

GMS coverage projections were produced by old health board region, sex, age cohort and three scenarios in five year intervals between 2016 and $2026^{3}$. Figure 3 estimates GMS coverage rates will lay between $29 \%$ and $43 \%$ in 2016, 31\% and $43 \%$ in 2021 and $33 \%$ and $46 \%$ in 2026. Coverage rates are estimated to be lower in 2016 due to slower population growth. The 2012 estimates of the mean claims rate and the average cost per claimant are available in the supplementary information file. The 2012 average cost per claimant for a male and female in the $>75$ age category is 15 and 18 times the average cost per claimant of a male and female in the 0-11 age category in the Eastern region, highlighting the variation in cost by age cohort.

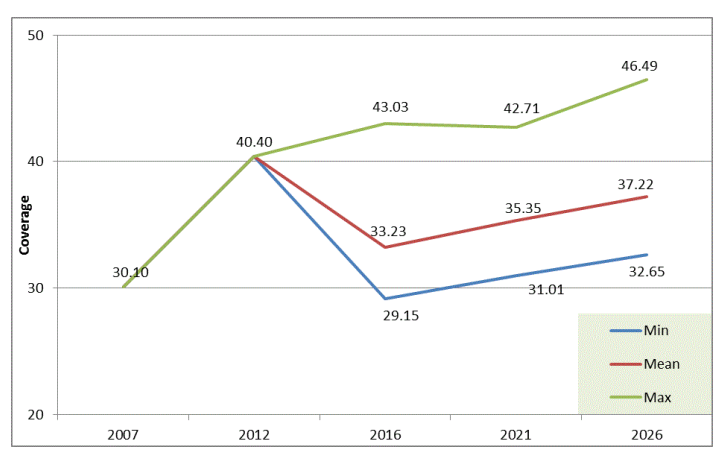

Figure 3: GMS Coverage Projections (\%) 2016-2026.

\section{GMS cost projections}

GMS cost projections are estimated to be $€ 1.1$ billion in 2016, €1.4 billion in 2021 and $€ 1.8$ billion in 2026 (most likely scenario) as illustrated in Figure 4. Lower CSO population projections based on lower fertility rates contributed to more conservative GMS cost projections.

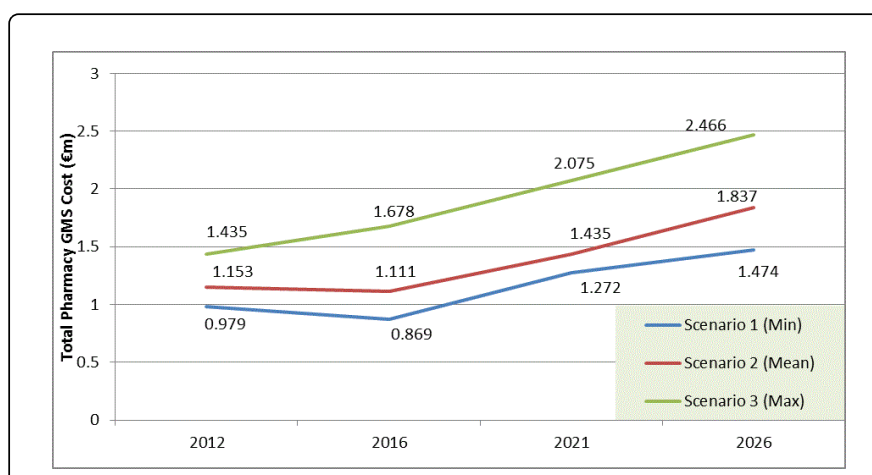

Figure 4: GMS Cost (€m) Projections 2016-2026.

1 Personal Communication: with a CSO population Statistician advised that males are experiencing higher growth rates than females in older age cohorts, as there more males than females in earlier age cohorts.

2 See Supplementary Information file for region (population proportion - \%) Population Projections $2012-2026$

3 See Supplementary Information file for 2026 GMS projections, most likely scenario. 
Page 5 of 7

\section{Monte carlo simulation results - descriptive and statistical analysis}

The descriptive analysis of 100,000 simulations for 2016, 2021 and 2026 is detailed in Table 2. There is considerable variation in the cost results with $25 \%$ of the data lying below $€ 46.02$ and $75 \%$ of the data lying above $€ 253.43$ in 2016 . The average cost per claimant is estimated to be $€ 249.96$ with the median estimated to be $€ 106.22$. The histogram plots the distribution of cost with a higher frequency of claimants having a lower average cost per claimant as illustrated in Figure 5.

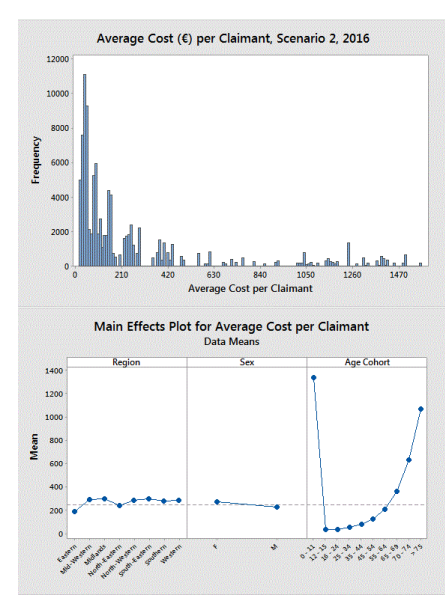

Figure 5: Histogram of Cost and Main effects Plot, Mean Scenario, 2016.

The histogram reiterates the descriptive analysis in Table 2, there is significant variation in cost with the lowest claim of $€ 21.25$ and the highest claim of $€ 1573.57$ in 2016. In Figure 5, the main effects plot examines the differences between the three categorical variables; old health board region, sex and age cohort. Sex is showing no main effect with all regions showing some effect except Eastern and NorthEastern. Age cohorts show the greatest response, especially under 11s, 65-69 and over 70s. Researchers further analysed these age groups and found that males, Mid-Western and South-Eastern regions are driving costs in the under 11s age group as illustrated in Figure 6.

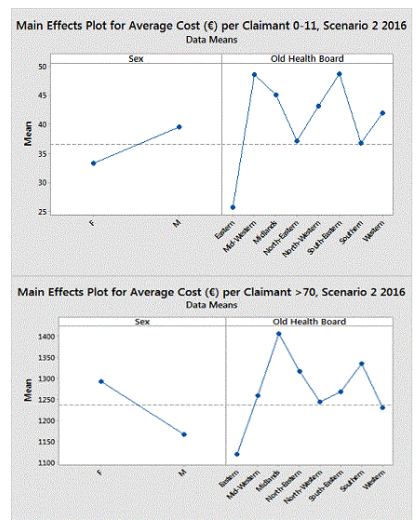

Figure 6: Main effects Plot by Sex and Old Health Board Region $<11$ and $>70$, Mean Scenario, 2016.
In Figure 6, females, the Midlands and Southern regions are driving costs in the over 70s. These results were also found in 2026.

\begin{tabular}{|l|l|l|l|l|l|}
\hline Year & \# of Simulations & Mean & St. Dev & Min & Q1 \\
\hline 2016 & 100,000 & 249.96 & 348.24 & 21.25 & 46.02 \\
\hline 2021 & 100,000 & 307.45 & 418.28 & 24.58 & 53.49 \\
\hline 2026 & 100,000 & 384.13 & 508.22 & 28.14 & 62.3 \\
\hline
\end{tabular}

Table 2: Descriptive Analysis of Average Cost per Claimant (€) 20162026 (Scenario 2- most likely scenario).

\section{Average cost per claimant $(€)$ by sex and region - Scenario 1- Scenario 3}

In Figure 7, the Midlands and the Southern regions are the most expensive and the Eastern and Western regions are the least expensive regions for all three scenarios. Females are driving costs more than males for all three scenarios. The under $11 \mathrm{~s}$ and increasing age are driving costs for all three scenarios. Similar trends were found for sex and age cohort in 2021 and 2026. In 2021 and 2026, the South-Eastern and the Midlands regions are estimated to be the most expensive and the North-Eastern and Eastern regions are estimated to be the least expensive regions.

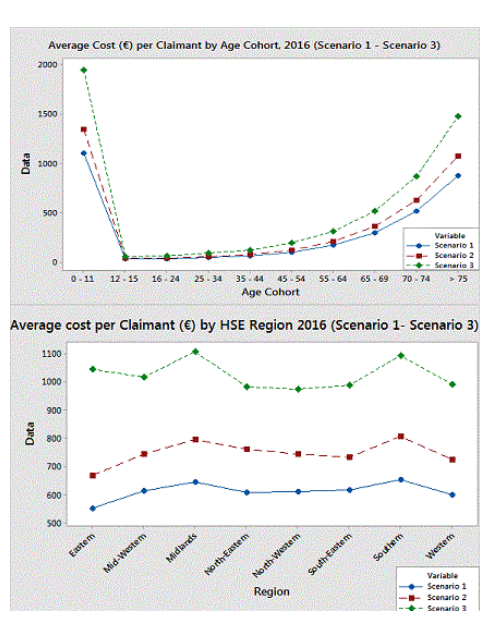

Figure 7: Average Cost per Claimant by Age Cohort, Region and Sex, and Scenarios 1-3 2016.

\section{Discussion}

The key findings of this research are; population growth, significant growth in the over 70s population, age, sex and region and the implications they will have in fuelling GMS costs. Irish population is projected to grow by approximately $10 \%$ between 2012 and 2026. The over 70 s population is estimated to grow by $64 \%$ with males over 70 estimated to grow by $72 \%$ over the projection period. A combination of falling rates of fertility and mortality produces a greater proportion of older people in society.An aging population will significantly contribute to overall GMS costs and has the potential to cause an increase in GMS coverage rates, claims rates and average cost per claimant. According to a WHO report, a key driver of health care costs is growth in the overall size of the population. Population aging is also 
a driver of health care costs, but not to the same extent [24]. An Irish study on aging reported that the dependency ratio was 0.18 in 2011 rising to 0.23 in 2021 [25]. Our estimates for 2021 show a similar finding, with a dependency ratio of 0.24 . This Irish study argued the inverse of the dependency ratio was more informative and they estimated a value of 5.7 in 2011 falling to 4.4 in 2021 [25]. In our study, the inverse is estimated to be 3.95 in 2021. An aging population, leading to an increased dependency ratio, will put financial pressures on future health costs. A French study found an increase in aging population and changes in health status will increase French drug expenditure annually by between $1.1 \%$ and $1.8 \%$ for the over $25 \mathrm{~s}$ [17].

A US study estimated health spending will grow on average by $5.8 \%$ annually to $\$ 2.4$ trillion between 2012 and 2022 based on a sluggish economic recovery in 2013 coupled with an expansion in coverage due to the Affordable Care Act and an aging population [13]. Two US studies projected drug expenditure and one study projected $12 \%$ to $14 \%$ increases in US total drug expenditures in clinics, and $5 \%$ to $7 \%$ increases in hospitals [16]. The other study predicted drug expenditure (ambulatory and hospital) would increase by $2 \%$ in 2010 and $4 \%$ in 2011 [18]. The current GMS cost projections are more conservative than the previous Irish projections [19]. Previous research estimated GMS cost projections will rise to $€ 1.3$ billion in 2016 , $€ 1.6$ billion in 2021 and $€ 1.9$ billion in 2026. This research estimated GMS cost projections will rise to $€ 1.1$ billion in 2016, €1.4 billion in 2021 and $€ 1.8$ billion in 2026 [19].

This research [19] found that females, age $(\leq 11$ and $\geq 70)$ and the Midlands region were driving GMS costs out to 2026. This paper confirms those findings and contributes the following; males, the MidWestern and South-Eastern regions are driving GMS costs in the under $11 \mathrm{~s}$ in 2016. Females, Midlands and Southern regions are driving GMS costs in the over 70s in 2016. Our results show that younger male children ( $\leq 11$ years) are a driver of GMS costs in Ireland. This may be explained by a higher incidence of drug prescribing amongst male children. An Irish study investigating prescribing antibiotics trends in a paediatric sub-population found that male participants (0-4 age cohort) were more likely to receive an antibiotic prescription than female participants [26]. A Spanish study examined how gender and age influenced prescription drug use and found a higher prevalence of prescription drugs in males aged $0-4$ and 5 to 14 years of age [11]. A Swedish study found more drugs were dispensed amongst males under 10 years [27]. In 2011, a new government was formed in Ireland with an objective of implementing a single-tier health service through the introduction of universal health insurance with free medical care for all [28]. In Budget 2015, the Irish government partially met this objective, by announcing free General Practitioner (GP) care for all children under 6 years of age. As this is one of the most expensive age groups, the Irish government may have been better advised to implement this policy in a less expensive age group such as adolescents as a pilot measure. Females over 70 years are driving GMS costs in Ireland. In Spain [11], Sweden [27] and British Colombia [29], there is a higher incidence of prescribing amongst females compared to males. The Spanish study found drug prescribing is $23 \%$ higher in females than males and that age is statistically more significant than sex $(\mathrm{P}<0.05)$ [11]. In British Colombia, they found that population aging only explained 1 point of the observed annual drug expenditure growth
[29]. The drug expenditure growth is largely explained by the increase in the age/sex specific numbers of prescriptions filled per patient and mix of products selected per prescription.

The Midlands region is the most expensive region and the Eastern region is the least expensive region for GMS costs. Upon further investigation at age cohort level, GMS costs differ across the eight regions. The Mid-Western and South-Eastern are the most expensive regions for the under $11 \mathrm{~s}$, the Midlands for the over $70 \mathrm{~s}$ and the Eastern region is the least expensive region for both age cohorts. A high prevalence of chronic conditions in the Midlands region [30] coupled with Usher et al. [31] findings that the Midlands and the MidWestern regions had the highest prescribing rates for type 1 and type 2 diabetes may explain high GMS expenditure in this region.

In terms of policies on cost containment, in November 2012, a three year agreement was formulated between the Irish Pharmaceutical Healthcare Association (IPHA), the Department of Health and the HSE. The agreement applies to medicines prescribed and reimbursed on the community drugs scheme, including the GMS. This agreement led to reductions in the cost of in-patent and off-patent pharmaceuticals [32]. It was widely reported that this agreement would yield over $€ 400$ million for the Irish state over three years. The Irish government estimated $€ 16$ million in drug savings in 2012 across all community drug schemes ${ }^{4}, € 116$ million in $2013, € 136$ million in 2014 and $€ 150$ million in 2015 [33]. According to a recent WHO report [4], the agreement resulted in actual savings of $€ 190$ million. Co-payments were introduced as a revenue raising measure. Two Irish studies found both co-payments ( $€ 0.50$ and $€ 1.50$ ) were associated with larger reductions in adherence to less--essential medicines than essential medicines, with anti-depressant and anxiolytic/hypnotic medicines being the exception $[34,35]$. In 2013, a number of cost containment measures were introduced. GMS eligibility income criteria were lowered, co-payment charges were increased and new legislation was enacted on reference pricing and generic substitution. These policy changes will reduce future GMS expenditure.

\section{Limitation}

The researchers investigated the possibility of developing estimates of the variables by the current regional HSE structure, which incorporates four regions (Dublin Mid-Leinster, Dublin North-East, and West and South). However, this was not possible for the Population variable ${ }^{5}$. Further research investigating the 2013 policy changes and the impact of the IPHA agreement on GMS expenditure would be very useful.

\section{Conclusion}

Growth in population and population aging will contribute to future GMS expenditure through the channels of increased average cost per claimant, GMS coverage and claims rates. However, cost containment measures; co-payment charges, generic substitution, reference pricing and GMS eligibility criteria can decelerate the pace of GMS expenditure growth. Co-payment charges are likely to reduce claims rates. Reference pricing and generic substitution are likely to reduce average cost per claimant and eligibility criteria will lower GMS

$4 \quad$ Minister for Health, James Reilly stated a breakdown in projected savings was not available by community drug scheme.

5 Personal Communication: with a CSO population Statistician and we were advised that the population data was only available by county but we required further disaggregation. For example, North Tipperary resides in HSE West and South Tipperary resides in HSE South. Therefore the research was based on the 8 old health board regions when further disaggregation was not available. 
coverage rates. The health sector in Ireland has a rapidly changing policy environment and this research went in some way to address these changes given the data that was at our disposal.

\section{References}

1. OECD (2014) Health at a glance: Europe.

2. OECD (2015) Government at a Glance, Technical report, OECD Publishing.

3. Brick, Gorecki P, Nolan A (2013) Ireland: Pharmaceutical Prices, Prescribing Practices and usage of Generics in a Comparative Context Dublin: Economic Social Research Institute Research Series.

4. Nolan A, Barry S, Burke S, Thomas S (2015) The Impact of the Financial Crisis on the Health System and Health in Ireland World Health Organisation European Observatory on Health Systems and Policies.

5. PCRS (2012) Primary Care Reimbursement Service: Statistical Analysis of Claims and Payments Dublin: Health Service Executive.

6. Keane (2014) Expert Panel on Medical Need for Medical Card Eligibility.

7. Barry M, Boland R, Bradley C, Devlin J, Hughes C, et al. (2009) Economies in Drug Usage in the Irish Healthcare Setting. Department of Health and Children.

8. DOH (2012) Health in Ireland - Key Trends 2012. Department of Health, 2012.

9. Gorecki P, Nolan A, Brick A, Lyons S (2012) Delivery of Pharmaceuticals in Ireland: Getting a Bigger Bang for the Buck Dublin: Economic and Social Research Institute, Policy Research Series.

10. F. H. Information (2012) Drivers of Prescription Drug Spending in Canada, Ottawa, Canada.

11. Liz-Fernadez. E, Modamio. P, Catalan. A, Lastra C. F, Rodriguez .T, et al. (2008) Identifying how age and gender influence prescription drug use in a primary health care environment in Catalonia Spain British Journal of Clinical Pharmacology 65: 407-417.

12. Loikas D, Wettermark B, von Euler M, Bergman U, Schenck-Gustafsson K (2013) Differences in drug utilisation between men and women: a cross-sectional analysis of all dispensed drugs in Sweden. BMJ Open 3.

13. Cuckler GA, Sisko AM, Keehan SP, Smith SD, Madison AJ, et al. (2013) National health expenditure projections, 2012-22: slow growth until coverage expands and economy improves. Health Affairs 32: 1820-1831.

14. Keehan SP, Cuckler GA, Sisko AM, Madison AJ, Smith SD, et al. (2012) National health expenditure projections: modest annual growth until coverage expands and economic growth accelerates. Health Affairs 167: 1000-1377.

15. Sisko AM, Keehan SP, Cuckler GA, Madison AJ, Smith SD, et al. (2014) National health expenditure projections, 2013-23: faster growth expected with expanded coverage and improving economy. Health Affairs 33: 1841-1850.

16. Schumock GT, Li EC, Suda KJ, Wiest MD, Stubbings J, et al. (2015) National trends in prescription drug expenditures and projections for 2015. Am J Health Syst Pharm 72: 717-736.

17. Thiebaut SP, Barnay T, Ventelou B (2013) Ageing, chronic conditions and the evolution of future drugs expenditure: a five-year micro-simulation from 2004 to 2029. Applied Economics 45: 1663-1672.
18. Wettermark B, Persson ME, Wilking N, Kalin M, Korkmaz S, et al. (2010) Forecasting drug utilization and expenditure in a metropolitan health region. BMC Health Serv Res 10: 128.

19. Conway A, Kenneally M, Woods N, Thummel A, Ryan M (2014) The implications of regional and national demographic projections for future GMS costs in Ireland through to 2026. BMC Health Serv Res 14: 477.

20. CSO (2013) Regional Population Projections 2016-2031.

21. CSO (2012) Vital Statistics Fourth Quarter and Yearly Summary 2012.

22. Sugiyama S (2007) Forecast Uncertainty and Monte Carlo Simulation. Foresight: The International Journal of Applied Forecasting 6: 29-37.

23. Bain LJ, Engelherdt M (1991) Introduction to Probability and Statistics (2nd ed): Duxbarry Thompson Learning.

24. Thomson S, Jowett M, Mladovsky P (2014) Health system responses to financial pressures in Ireland, Policy Options in an International Context. World Health Organisation (WHO).

25. Barrett A, Burke H, Cronin H, Hickey A, Yumiko K, et al. (2011) Fifty plus in Ireland 2011. First results from the Irish Longitudinal Study on Ageing Dublin: TILDA, 2011.

26. Keogh C, Motterlini N, Reulbach U, Bennett K, Fahey T (2012) Antibiotic prescribing trends in a paediatric sub-population in Ireland. Pharmacoepidemiol Drug Saf 21: 945-952.

27. Loikas D, Wettermark B, von Euler M, Bergman U, Schenck-Gustafsson $\mathrm{K}$ (2013) Differences in drug utilisation between men and women: a cross-sectional analysis of all dispensed drugs in Sweden. BMJ Open 3.

28. Government of Ireland (2011)Government for National Recovery 2011-2016 Dublin: Stationary Office.

29. Morgan SG (2006) Prescription drug expenditures and population demographics. Health Serv Res 41: 411-428.

30. Naughton C, Bennett K, Feely J (2006) Regional variation in prescribing for chronic conditions among an elderly population using a pharmacy claims database. Ir J Med Sci 175: 32-39.

31. Usher C, Bennett K, Feely J (2005) Regional variation in the prescribing for diabetes and use of secondary preventative therapies in Ireland. Pharmacoepidemiol Drug Saf 14: 537-544.

32. IPHA (2012) Framework agreement between the Irish Pharmaceutical Healthcare Association Ltd and the Department of Health and the Health Service Executive on the supply terms, conditions and prices of medicines.

33. Oireachtas (2012) Dail question response to Thomas Broughan from Minister James Reilly.

34. Sinnott SJ, Guinane M, Whelton H, Byrne S (2013) Is 50 cent the price of the optimal copayment? a qualitative study of patient opinions and attitudes in response to a 50 cent charge on prescription drugs in a publicly funded health system in Ireland. BMC Health Services Research.

35. Sinnott SJ, Buckley C, O'Riordan D, Bradley C, Whelton H (2013) The effect of copayments for prescriptions on adherence to prescription medicines in publicly insured populations; a systematic review and metaanalysis. PLoS One 8: e64914. 